\title{
Development and Bioavailability Assessment of Ramipril Nanoparticle Formulation
}

\author{
Annie Pereira, Anand Panchakshari Gadad ${ }^{*}$, Archana Sidagouda Patil, Panchakshari Mallappa \\ Dandagi
}

Department of Pharmaceutics, KLE College of Pharmacy, KLE Academy of Higher Education and Research (Deemed-to-be-University), Nehru Nagar, Belgagavi-590010, Karnataka, INDIA.

\begin{abstract}
Ramipril, potent anti-hypertensive agent has been used in the treatment of hypertensive disorders. It has low bioavailability of $28-35 \%$ and short biological half-life (i.e. 2-4 hr). Thus this study attempts to evaluate chitosan-alginate nanoparticles as a novel drug delivery for Ramipril to sustain drug release and improve oral bioavailability. Nanoparticles were prepared by ionotropic pre-gelation technique using chitosan and sodium alginate polymers. Total nine formulations (F1 to F9) were prepared by varying the polymer concentrations. The nanoparticles were characterized for particle size, drug content, drug entrapment efficiency, zeta potential, surface morphology (TEM), percentage yield, in-vitro diffusion study, in-vivo bioavailability studies and stability studies. All prepared formulations were in the nanosize range of $190.5 \pm 6.15 \mathrm{~nm}$ to $361.76 \pm 3.32$ and with spherical morphology. The drug content and entrapment efficiency was found to maximum for F5 formulation, percentage yield was in the range of $53.72 \pm 2.04$ to $77.91 \pm 0.565 \%$ which mainly depends upon polymer concentration. The zeta potential of optimised formulation F5 was found to be $-34.2 \mathrm{mV}$, showed good stability of nanoparticles during storage. The in-vitro drug release profile showed the suitability of nanoparticles for $\mathrm{pH}$ dependent and sustained release of Ramipril for prolonged time. Kinetic modelling revealed that the in-vitro drug release followed peppas model and non-fickian diffusion. From the in vivo studies it was predicted that oral bioavailability of Ramipril nanoparticles improved 2.17 times more than the pure drug. Stability studies carried out for optimized formulation F5 showed that the nanoparticles are more stable at $5 \pm 3^{\circ} \mathrm{C}$.
\end{abstract}

Key words: Ramipril, Chitosan, Sodium alginate, Ionotropic pre-gelation technique, Chitosan-alginate polymeric complex, $\mathrm{pH}$ sensitive, Oral bioavailability.

\section{INTRODUCTION}

Ramipril, potent anti-hypertensive agent has been used in the treatment of hypertensive disorders. It belongs to Angiotensin-Converting Enzyme (ACE) inhibitor class. It act by selectively suppressing renin-angiotensin-aldosterone system, inhibit ACE, prevents conversion of angiotensin I to angiotensin II, resulting in dilation of arterial and venous vessel. It is highly lipophilic (log p octanol/water, 3.32), poorly water soluble drug with absolute bioavailability of 28-35\%. Ramipril has a low bioavailability and also short biological half-life (i.e. 2-4 hr) with fluctuations in plasma concentra- tions and its significant first-pass metabolism when taken orally. ${ }^{1}$ Conventional drug delivery system has been characterized by immediate release and repeated dosing of the drug which might lead to the risk of dose fluctuation. ${ }^{2}$ Nanoparticles exhibit enhanced size-dependent properties compared with larger particles of the same material. The main objectives of designing nanoparticles as a drug delivery system are to control particle size, surface properties and to deliver pharmacologically active agents at right place, at the rational rate and dose ${ }^{3,4}$ Chitosan (CS) is a natural cationic
Submission Date: 23-06-2015; Revision Date: 29-02-2016; Accepted Date: 28-10-2016

DOI: 10.5530/ijper.53.4s.154 Correspondence:

Dr. A. P. Gadad,

Professor and Head Department of Pharmaceutics,

KLE College of Pharmacy, KLE Academy of Higher Education and Research (Deemed-to-be-University), Nehru Nagar, Belgagavi590010, Karnataka,INDIA. Phone: +91 9448309472

E-mail: gadadap@rediffmail. com

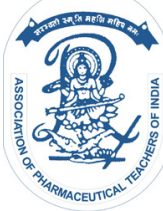

www.ijper.org 
polysaccharide obtained by the N-deacetylation of chitin, a product found in the shells of crustaceans the primary amine groups provide special properties that make CS very useful in pharmaceutical applications. The addition of CS can not only endow nanoparticles positive surface charge, but also prolong the time for which active ingredients are in contact with the epithelium and thus enhance absorption via the para-cellular transport pathway through the tight junctions..$^{5-7}$ Alginate (ALG) is a water soluble linear polysaccharide extracted from brown sea weed and is composed of alternating blocks of 1-4 linked $\alpha$-L-guluronic and $\beta$-D-mannuronic acid residues. Alginates which are a group of hemocompatible polymers have not been found to accumulate in any major organs and have shown evidence of in vivo degradation. The guluronic acid residues of alginate in the presence of calcium ion undergo ionic interaction to form gels. The properties of calcium-alginate gel beads make them one of the most widely used carriers for controlled release systems. ${ }^{6,8}$ Nanoparticles prepared from alginate alone show low stability and encapsulation efficiency, but these problems can be overcome using cationic polymers such as chitosan. Chitosan-alginate polymeric complex are formed due to ionic interaction between the carboxylate groups of alginate and the ammonium groups of chitosan. The formed nanoparticles are biocompatible, biodegradable, non-toxic and capable to sustain the release of encapsulated materials more efficiently than either alginate or chitosan alone. ${ }^{9}$ This necessitated the development of novel chitosanalginate nanoparticles as novel drug delivery system for Ramipril in order to provide $\mathrm{pH}$ dependent, sustained drug release and increase oral bioavailability.

\section{MATERIALS AND METHODS}

\section{Materials}

Ramipril was procured as gift sample from Unichem Laboratories, Goa. Sodium alginate was obtained as a gift sample from Hariharathmaja Chemical Works, Kochi. Chitosan (high viscosity) was purchased from Central Institute of Fisheries Cochin, Kerala. All other reagents used were of analytical grade.

\section{Experimental MethodsPreparation of Chitosan- Alginate nanoparticles}

Chitosan-Alginate nanoparticles were prepared by ionotropic pregelation technique. Briefly specified quantity of sodium alginate and calcium chloride are dissolved in distilled water separately. The $\mathrm{pH}$ of the sodium alginate solution was adjusted to 5.1 using $1 \mathrm{M}$ hydrochloric acid. Briefly, a known amount of chitosan was dissolved in $1 \%$ acetic acid solution and $\mathrm{pH}$ was modified to 5.4 using $0.1 \mathrm{~N} \mathrm{NaOH}$. Calcium chloride, a cross linking agent, was added dropwise to $15 \mathrm{ml}$ of sodium alginate solution $(0.06-0.1 \% \mathrm{w} / \mathrm{v})$ containing Ramipril [initially dissolved in $2 \mathrm{ml}$ of ethanol: water (1:1) mixture], under stirring condition. To this $3 \mathrm{ml}$ of $0.5 \% \mathrm{w} / \mathrm{v}$ of Pluronic F-68 was added to above solution. Then chitosan solution $3 \mathrm{ml}$ of $(0.03-0.07 \% \mathrm{w} / \mathrm{v})$ was added dropwise to resultant solution (Table 1) followed by probe sonication for $30 \mathrm{~min}$ and the mixture was kept at room temperature overnight for uniform particle size distribution. ${ }^{5,10}$

\section{Evaluation of Ramipril chitosan alginate nanoparticles Determination of particle size and Polydispersity index}

The size distribution and polydispersity index (PDI) of the formulations was measured by Dynamic Light Scattering Particle Size Analyzer (Nano-flex, Microtrac Inc., USA). The range of the analyzer is $0.02 \mathrm{~nm}$ to $2.8 \mu \mathrm{m}$. The average diameter and a measure of the distribution width (polydispersity) were determined from the particle size distribution data. Polydispersity index varies from 0.0 to 1.0. The closer to zero the polydispersity value, the more homogenous are the particles. The usual range of PDI values: 0-0.05 (monodisperse standard),

\begin{tabular}{|c|c|c|c|c|c|c|c|c|c|}
\hline \multirow[t]{2}{*}{ Ingredients } & \multicolumn{9}{|c|}{ Formulation code } \\
\hline & F1 & F2 & F3 & F4 & F5 & F6 & F7 & F8 & F9 \\
\hline Ramipril $(m g)^{*}$ & 10 & 10 & 10 & 10 & 10 & 10 & 10 & 10 & 10 \\
\hline Sodium Alginate (mg) & 9 & 12 & 15 & 9 & 12 & 15 & 9 & 12 & 15 \\
\hline Chitosan $(m g)^{* *}$ & 0.9 & 0.9 & 0.9 & 1.5 & 1.5 & 1.5 & 2.1 & 2.1 & 2.1 \\
\hline Calcium chloride $(18 \mathrm{mM})(\mathrm{ml})$ & 1 & 1 & 1 & 1 & 1 & 1 & 1 & 1 & 1 \\
\hline Pluronics $68(0.5 \%)(\mathrm{ml})$ & 3 & 3 & 3 & 3 & 3 & 3 & 3 & 3 & 3 \\
\hline Distilled water $(\mathrm{ml})$ & \multicolumn{9}{|c|}{ Make up the volume up to $25 \mathrm{ml}$} \\
\hline
\end{tabular}

*Ramipril dissolved in ethanol and water mixture (1:1) ** Chitosan dissolved in $1 \%$ acetic acid. 
0.05-0.08 (nearly-monodisperse), 0.08-0.7 (midrange polydispersity), $>0.7$ (very polydisperse). ${ }^{11,12}$

\section{Determinations of drug content}

A quantity of drug loaded nanoparticles equivalent to $1 \mathrm{mg}$ was added to $10 \mathrm{ml}$ mixture of methanol and phosphate buffer pH 6.8 (1:10) and stirred continuously for $2 \mathrm{hr}$ and then the final colloidal suspensions were ultracentrifuged at $10000 \mathrm{rpm}$ for half an hour. The supernatant was analysed for drug content by measuring the absorbance at $207 \mathrm{~nm}$ using UV spectrophotometer. ${ }^{13}$

\section{Entrapment efficiency}

The encapsulation efficiency of nanoparticles was determined by the separation of drug-loaded

Nanoparticles from the aqueous medium containing non-associated Ramipril by ultracentrifugation at 12,000 $\mathrm{rpm}$ at $4^{\circ} \mathrm{C}$ for $1 \mathrm{hr}$. The amount of Ramipril loaded into the nanoparticles was calculated as the difference between the total amount used to prepare the nanoparticles and the amount that was found in the supernatant. The amount of free Ramipril in the supernatant was measured by UV Spectrophotometer. ${ }^{14}$ Entrapment efficiency was then calculated as follows:

Entrapment efficiency was calculated by Eq.1

$$
\% E E=\frac{\text { total amount of drug }- \text { non bound drug }}{\text { total amount of drug added }} \times 100 \ldots . . . E q 1
$$

\section{Percentage yield}

Fixed volumes of Ramipril nanosuspension were centrifuged at $9000 \mathrm{rpm}$ for $30 \mathrm{~min}$ at $15^{\circ} \mathrm{C}$. The obtained sediment was dried and weighed. ${ }^{11,15}$ The percentage yield was calculated by Eq.2

$$
\text { Perecentage Yield }=\frac{\text { weight of nanoparticles obtained }}{\text { weight of drug and excipient }} \times 100 \ldots . . \text { Eq..2 }
$$

\section{Shape and Surface Morphology}

\section{Transmission electron microscopy (TEM)}

External morphology of Nanoparticles was determined using Transmission electron microscopy (TEM) at Punjab University, Chandigarh. Samples of Nanoparticles were prepared by placing one drop on a copper grid, without being stained before being examined using TEM. ${ }^{16}$

\section{Zeta potential}

The zeta potential value of optimized Ramipril loaded chitosan- alginate (CS-ALG) nanoparticle formulation was measured with the Zetasizer. To determine the zeta potential, optimized formulation was diluted with double-distilled water and placed in an electrophoretic cell. ${ }^{17}$

\section{In vitro drug release}

The release of Ramipril from nanoparticles was evaluated using USP type II paddle apparatus over $24 \mathrm{hr}$, dialysis membrane was loaded with nanoparticle formulation containing $10 \mathrm{mg}$ equivalent of drug, which was suspended initially for $2 \mathrm{hrs}$ in $900 \mathrm{ml}$ of $0.1 \mathrm{NHCl}$ buffer of $\mathrm{pH} 1.2$ and then in $\mathrm{pH} 6.8$ phosphate buffer upto $24 \mathrm{hr}$ maintained at $37 \pm 0.5^{\circ} \mathrm{C}$ and $50 \mathrm{rpm}$. At regular intervals aliquots of $1 \mathrm{ml}$ of the sample were withdrawn and replaced with the same volume of the respected fresh buffer solution. The amount of released drug was assessed by UV-1700 analysis at $207 \mathrm{~nm}$ (Shimadzu UV-1700, Japan) after dilution.

\section{In vivo studies}

Healthy male wistar rats weighing 180-200 gm were housed in polypropylene cages and maintained at room temperature under $12 \mathrm{hr}$ dark/light cycles. They were fed with standard pelleted diet and water. The animals were acclimatized for one week under laboratory conditions before experiments on the animals. Ethical clearance was obtained from the Institutional Animal Ethics Committee (Resolution No: KLECOP/IAEC/Res.2009/08/2014) prior to the beginning of research work. This study was aimed mainly to estimate the amount of drug in the blood withdrawn from rats at various time intervals. ${ }^{18}$ Dose for animal

Dose conversion formula from human dose to animal dose (Rat)

Rats Dose $=$ Human Dose $\times$ Factor (0.018) Eq ....3

The animals were divided into 2 groups

Group 1: Received pure drug Ramipril 1.08mg for 6 animals in normal saline through oral route.

Group 2: Received nanoparticles containing equivalent to $1.08 \mathrm{mg}$ of Ramipril for 6 animals in normal saline through oral route.

After 0.5, 1, 2, 4, 8, 12 and $24 \mathrm{hr} 0.5-1 \mathrm{ml}$ blood was collected from eye by retro-orbital puncture. Blood was taken in Eppendorf containing $0.1 \mathrm{ml}$ of $4 \% \mathrm{w} / \mathrm{v}$ of sodium citrate solution and centrifuged at $5000 \mathrm{rpm}$ for 10 min supernatant plasma was collected and acetonitrile was added for precipitating the plasma proteins and vortexed for $1 \mathrm{~min}$ and then centrifuged at 13,000rpm for $15 \mathrm{~min}$ and supernatant solution was collected and analyzed in HPLC.

\section{HPLC method development for analysis of Ramipril in plasma samples}

\section{Instrument}

A Shimadzu prominenece HPLC system (Shimedzu, Kyoto, Japan) equipped with LC-20AD quartenary 
pump, DGU-20A5 online prominence degasser, SPDM20A photodiode array detector, SIL-20AC HT Autosampler, Rheodyne injection valve with $20 \mu$ l loop and CTO-10ASVP-column oven. Software-LC solution V.1.25.

\section{Chromatographic Conditions}

Sheseido column $\mathrm{C}_{18}$ column 250 x $4.6 \mathrm{~mm}, 5 \mu$ diameter was used for separation. The mobile phase containing $0.2 \%$ orthophosphoric acid: acetonitrile in the ratio of $50: 50(\mathrm{v} / \mathrm{v})$ was delivered at a flow rate $0.6 \mathrm{ml} / \mathrm{min}$ and the elution was monitored at $205 \mathrm{~nm}$. Injection volume was $20 \mu \mathrm{l}$. Pressure of $65 \mathrm{~kg} / \mathrm{cm}^{2}$ and temperature $28^{\circ} \mathrm{C}$.

\section{Preparation of $0.2 \%$ orthophosphoric acid}

Measure $2000 \mu \mathrm{l}$ of orthophosphoric acid in $1000 \mathrm{ml}$ clean dry beaker and make up volume to $1000 \mathrm{ml}$ with HPLC water.

\section{Preparation of mobile phase}

Mix a mixture of above solution i.e. $0.2 \%$ orthophosphoric acid $500 \mathrm{ml}(50 \%)$ and $500 \mathrm{ml}$ of Acetonitrile HPLC $(50 \%)$ and degas in ultrasonic water bath for 5 min. Filter through $0.45 \mu$ filter under vacuum filtration.

\section{Standard solutions and spiked samples}

Accurately weigh and transfer $10 \mathrm{mg}$ of Ramipril in $10 \mathrm{ml}$ clean dry volumetric flask add about $5 \mathrm{ml}$. Acetonitrile, sonicate to dissolve it completely and make volume up to the mark with $0.2 \%$ orthophosphoric acid. Further pipette out $10 \mu \mathrm{l}, 20 \mu \mathrm{l}, 30 \mu \mathrm{l}, 40 \mu \mathrm{l}, 50 \mu \mathrm{l}$ and $60 \mu \mathrm{l}$ of the above stock solution into a $2 \mathrm{ml}$ eppendorf tube and dilute up to the mark with mobile phase to obtain workingstock solutions of concentration $5 \mu \mathrm{g} /$ $\mathrm{ml}, 10 \mu \mathrm{g} / \mathrm{ml}, 15 \mu \mathrm{g} / \mathrm{ml}, 20 \mu \mathrm{g} / \mathrm{ml}, 25 \mu \mathrm{g} / \mathrm{ml}$ and 30 $\mu \mathrm{g} / \mathrm{ml}$. Standard solutions $(1 \mu \mathrm{g} / \mathrm{ml}, 2 \mu \mathrm{g} / \mathrm{ml}, 3 \mu \mathrm{g} / \mathrm{ml}, 4$ $\mu \mathrm{g} / \mathrm{ml}, 5 \mu \mathrm{g} / \mathrm{ml}$ and $6 \mu \mathrm{g} / \mathrm{ml}$ ) were prepared by spiking $200 \mu \mathrm{l}$ of working solution $(5 \mu \mathrm{g} / \mathrm{ml}, 10 \mu \mathrm{g} / \mathrm{ml}, 15 \mu \mathrm{g} /$ $\mathrm{ml}, 20 \mu \mathrm{g} / \mathrm{ml}, 25 \mu \mathrm{g} / \mathrm{ml}$ and $30 \mu \mathrm{g} / \mathrm{ml}$ ) into $200 \mu \mathrm{l}$ of blank plasma and $600 \mu \mathrm{l}$ acetonitrile. These standards were used to construct calibration curve in plasma.

\section{Plasma sample preparations}

$100 \mu \mathrm{l}$ of plasma containing unknown concentration of drug (withdrawn from rats at different time interval) were pipetted using micropipette into $2 \mathrm{ml}$ eppendorf tube. To this $200 \mu \mathrm{l}$ of acetonitrile was added to precipitate protein present in the plasma. This solution was capped and mixed by vortexing at high speed for $1 \mathrm{~min}$. Next all tubes were centrifuged at $13,000 \mathrm{rpm}$ for $15 \mathrm{~min}$ in eppendorf minispin centrifuge, After centrifugation the upper organic layer was filtered through $0.2 \mu \mathrm{m}$ membranes into clean vials and a volume of $20 \mu \mathrm{l}$ was injected into HPLC system.

\section{Short term stability studies}

Optimized formulation was chosen to perform short term stability studies. Samples were stored in glass vials for 3 months at $5 \pm 3^{\circ} \mathrm{C}$ in freeze and at $30 \pm 2{ }^{\circ} \mathrm{C} / 65 \pm 5 \%$ RH. After 30,60 and 90 days samples were observed for particle size, $\%$ entrapment efficiency and drug release were carried out for optimized formulation at every one month interval. ${ }^{19}$

\section{RESULTS AND DISCUSSION}

\section{Preparation of chitosan-sodium alginate nanoparticles}

The chitosan-alginate nanoparticles are successfully prepared by ionotropic gelation technique. Preparation is simple, rapid and reliable. A number of trials were carried out inorder to obtain appropriate concentration range of polymers so as to allow the formation of turbid solutions and not the aggregates. The final concentration range selected $0.03-0.07 \% \mathrm{w} / \mathrm{v}$ and $0.06-0.1 \%$ $\mathrm{w} / \mathrm{v}$ for CS and ALG, respectively. Chitosan-alginate (CS-ALG) polyionic complexes are formed through the ionic gelation via interactions between the carboxyl groups of alginate and the amine groups of chitosan. ${ }^{5,8}$ The effect of $\mathrm{pH}$ on the nanoparticles formulation was studied by Douglas and Tabrizian. It was found that size of nanoparticle was smaller when alginate solution of pH 5.3 was combined with chitosan solution $\mathrm{pH}$ 5.5. This may be explained by the fact low solubility of chitosan in water at neutral and alkaline $\mathrm{pH}$ hence the chitosan solution is prepared in acidic conditions. Due to this there are chances of chitosan precipitating upon addition of alginate solution with higher $\mathrm{pH}$ resulting in less Chitosan available for nanoparticles formation. Also as the pKa of Chitosan is reported to be 6.5, addition of alginate solution with neutral $\mathrm{pH}$ would result in the majority of amine groups of CS being unprotonated and, therefore, unable interact with ALG. Thus using alginate at slightly lower $\mathrm{pH}(5.0-5.3)$ will overcome this problem allowing stronger interaction between chitosan and alginate. Motwani K S et al. observed that if alginate and chitosan solution were used in more acidic ranges results in larger size particles and smaller nanoparticles when both polymers have a $\mathrm{pH}$ range of 5.1-5.7. Within this range, the amine groups of the chitosan are protonated and the carboxyl groups of the alginate are ionised, which is most important for optimum interaction and the polyionic complex formation. ${ }^{3}$ 


Table 2: Particle size, pdi, drug content, \% yield and \% ee values of ramipril nanoparticles formulations F1 to
\begin{tabular}{|c|c|c|c|c|c|}
\hline Formulation & Particle size (nm) & PDI & $\%$ Yield & Drug content & $\%$ EE \\
\hline F1 & $190.5 \pm 6.15$ & $0.500 \pm 0.02$ & $53.72 \pm 2.04$ & $88.93 \pm 1.84$ & $43.75 \pm 0.62$ \\
\hline F2 & $206.73 \pm 5.94$ & $0.447 \pm 0.051$ & $57.61 \pm 0.71$ & $90.16 \pm 4.304$ & $52.5 \pm 0.40$ \\
\hline F3 & $237.9 \pm 3.78$ & $0.719 \pm 0.04$ & $59.7 \pm 1.10$ & $88.52 \pm 2.28$ & $62.5 \pm 0.81$ \\
\hline F4 & $248.9 \pm 6.45$ & $0.207 \pm 0.071$ & $62.60 \pm 0.69$ & $93.44 \pm 1.22$ & $74 \pm 0.40$ \\
\hline F5 & $258.76 \pm 4 . .36$ & $0.149 \pm 0.036$ & $68.05 \pm 1.50$ & $96.72 \pm 0.853$ & $86.7 \pm 0.52$ \\
\hline F6 & $302.36 \pm 6.03$ & $0.269 \pm 0.04$ & $70.88 \pm 1.22$ & $89.75 \pm 4.10$ & $69.7 \pm 1.08$ \\
\hline F7 & $319.86 \pm 7.04$ & $0.723 \pm 0.74$ & $73.20 \pm 0.45$ & $95.49 \pm 6.97$ & $77.5 \pm 1.03$ \\
\hline F8 & $349.4 \pm 3.35$ & $0.149 \pm 0.307$ & $76.01 \pm 0.98$ & $94.6 \pm 1.25$ & $64.5 \pm 0.62$ \\
\hline F9 & $361.76 \pm 3.32$ & $0.570 \pm 0.08$ & $77.91 \pm 0.56$ & $93.0 \pm 0.012$ & $62 \pm 0.40$ \\
\hline
\end{tabular}

*Data are expressed as mean \pm S.D. $(n=3)$

\section{Particle size and Size distribution}

The mean particle size for formulations F1 to F9 varied in range of $190.5 \pm 6.15$ to $361.76 \pm 3.32$ (Table 2). It was observed that mean particle size increases with the increase in the polymer concentration upto a level. Further increase in the polymer concentration above the concentration range mentioned resulted in the aggregation of the particles. The mean polydispersity index values for the Ramipril loaded chitosan alginate nanoparticle formulations F1 to F9 are in the range of 0.1499- 0.723 as shown in (Table 2). The results of PDI can be simultaneously checked with particles size analysis. A monodisperse sample indicates PI value nearer to 0 . However, PDI $<1$ indicates polydisperse samples. Therefore, PI measurement was essential to confirm the size distribution of the particles.,

\section{Drug content}

Drug content varies in the range of $88.52 \pm 2.28$ to $96.72 \pm 0.853$ and was determined using the UV spectroscopic analysis at $207 \mathrm{~nm}$.

\section{Entrapment efficiency}

Encapsulation efficiency of the nanoparticles was found to vary between $43.75 \pm 0.62$ and $86.7 \pm 0.52$. Motwani $\mathrm{S} \mathrm{K}$ et al. suggested that at intermediate concentration of chitosan and sodium alginate the encapsulation of drug was maximum. The percent entrapment efficiency increases from F1 to F5 and then decreases from F6 to F9. This is because increase in the polymer concentration causes increase in the drug entrapment upto a level, further increase in the polymer concentration leads to decrease in the entrapment efficiency which can be explained on the basis of the fact that at higher concentrations of the two polymers, it is polymers that make the bulk of the nanoparticles matrix and less volume is available for drug encapsulation. Formulation F5 (86.7 \pm 0.52$)$ show maximum entrapment efficiency.
Based on entrapment efficiency and drug content formulation F5 was taken as optimized formulation.,

\section{Percentage yield}

Percentage yield was found to be $53.72 \%$ to $77.91 \%$ for formulation F1 to F9 (Table 2). Percentage practical yield depends on the concentration of polymer added, as the concentration of polymer increases there is increases in the $\%$ yield. Maximum yield obtained is $77.91 \%$ for formulation F9.

\section{TEM Analysis}

Optimized formulation F5 containing chitosan (0.05\%) and sodium alginate $(0.08 \%)$ was subjected to TEM with different resolution. In the magnification of $10000 \times$ particles were small, spherical (Figure 1) and discrete while the same formulation at $30000 \times$ magnification the surface was seen to be smooth and spherical with the size range of $245 \mathrm{~nm}$ and $253 \mathrm{~nm}$.

\section{Zeta potential}

Zeta potential is an important parameter to analyze the long-term stability of the nanoparticles. It refers to the surface charge of the particles. Zeta potential of nanoparticles is of significance on stability in suspension through the electrostatic repulsion between the particles. Zeta potential of the optimized formulation F5 was found to be $-32.2 \mathrm{mV}$ (Figure 2). The zeta potentials of about $-34.2 \mathrm{mV}$ indicate good stability of formulation. This might be attributed to surfactant which decreases the electrostatic repulsion between the particles and sterically stabilizes the nanoparticles by forming a coat around their surface. ${ }^{20}$

\section{In vitro drug release}

In vitro drug release from the nanoparticles was initially carried out in $0.1 \mathrm{~N} \mathrm{HCl}$ buffer $\mathrm{pH} 1.2$ for $2 \mathrm{hrs}$ followed by Phosphate buffer pH 6.8 upto 24 hr, it was 


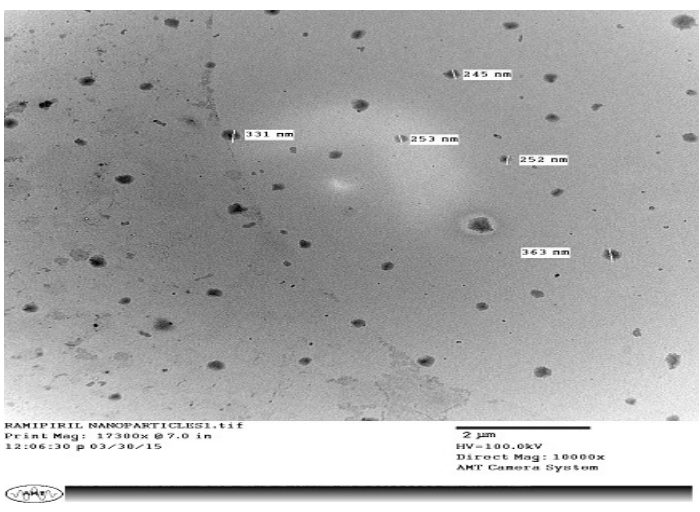

Figure 1: TEM of optimized formulation F5.

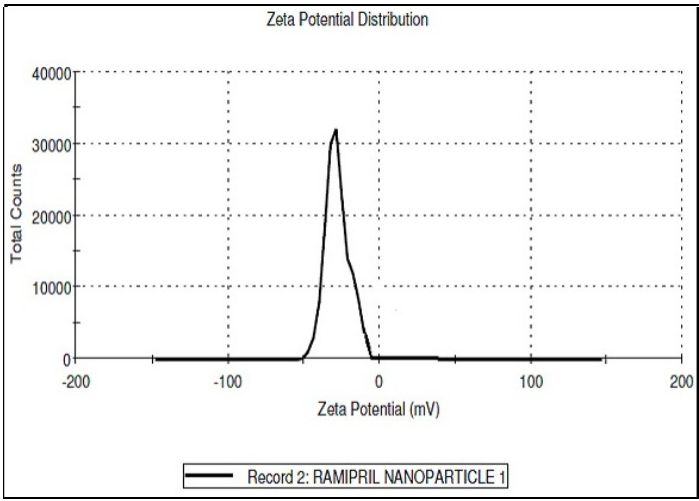

Figure 2: Zetapotential of optimized formulation (F5).

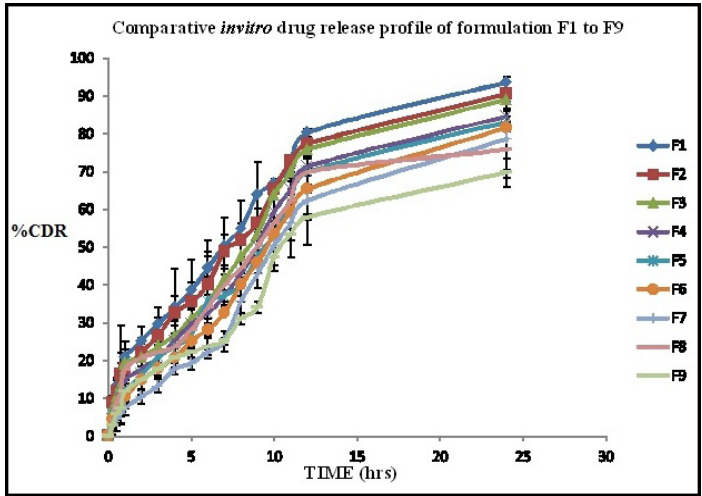

Figure 3: Comparative in vitro drug release profile of F1 to F9.

performed using dialysis bag diffusion technique. The drug release at the end of $2 \mathrm{hrs}$ in $0.1 \mathrm{~N} \mathrm{HCl} \mathrm{pH} 1.2$ for $\mathrm{F} 1-25.14 \%, \mathrm{~F} 2-22.25 \%, \mathrm{~F} 3-20.71 \%, \mathrm{~F} 4-17.74 \%$, F5-16.2\%, F6-14.7\%, F7-10.35\%, F8-20.7\%, F9-14.7\% and at the end of $24 \mathrm{hrs}$ the mean cumulative drug release was F1-93.63\%, F2-90.6\%, F3-89.12\%, F4-84.6\%, F5-83.14\%, F6-81.62\%, F7-78.6\%, F8-75.7\%, F9-69.7\% (Figure 3). It was observed that at low polymer concentration i.e. F1 showed maximum release at the end of $24 \mathrm{hr}$. As the polymer concentration increases from F1 to $\mathrm{F} 9$ the release decreases, this is mainly due to higher

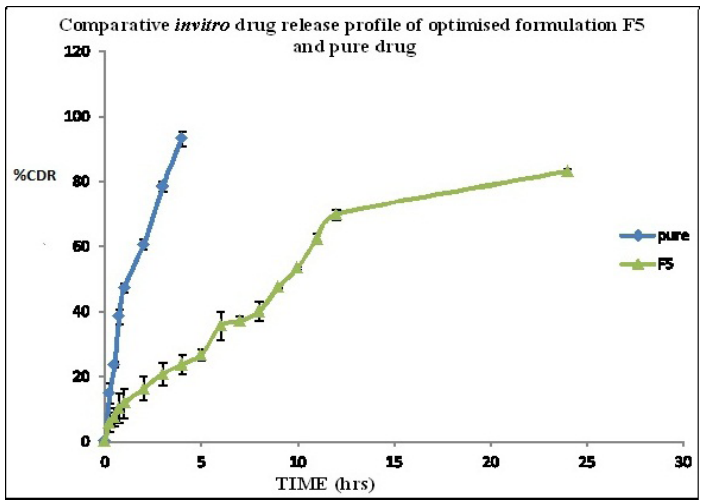

Figure 4: Comparative in vitro drug release profile of optimized formulation $\mathrm{F} 5$ and pure drug.

\begin{tabular}{|c|c|c|c|}
\hline $\begin{array}{c}\text { Table 3: Pharmacokinetic parameter of pure ramipril } \\
\text { and optimized formulation f5. }\end{array}$ \\
\hline Formulations & $\begin{array}{c}\mathbf{C}_{\max }(\mathbf{m c g} / \\
\mathbf{m l})\end{array}$ & $\mathbf{T}_{\max }(\mathbf{h})$ & $\begin{array}{c}\mathbf{A U C}_{\text {0-t }} \text { (mcg/ } \\
\mathbf{m l} . \mathbf{h})\end{array}$ \\
\hline Pure Ramipril & 7.9768 & $0.5 \mathrm{hrs}$ & 114.874 \\
\hline $\begin{array}{c}\text { Optimized } \\
\text { formulation F5 }\end{array}$ & 12.482 & $8 \mathrm{hrs}$ & 249.77 \\
\hline
\end{tabular}

polymer concentration the drug will take longer time to diffuse out.

The initial release of the drug at the end of $2 \mathrm{hr}$ may be due to the drug present on the surface of Nanoparticles. Whereas the drug which is present in the matrix inside the nanoparticles have additional barrier due to the polyelectrolyte complex which remains intact at acidic $\mathrm{pH}$ and when the nanoparticles are exposed to phosphate buffer pH 6.8 the polyelectrolyte complex weaken and there is slow release of drug for a prolong period of time. ${ }^{21}$

Evaluation of the release profiles of pure drug showed that almost all the Ramipril was released immediately during first $4 \mathrm{hrs}$, suggesting that the developed nanoparticles can be used as an important platform for sustained drug release. (Figure 4)

Among the models tested, the drug release profiles for formulations (F1 to F9) were best fitted with Korsmeyer- Peppas model based on regression coefficients (0.9923, 0.9890, 0.9810, 0.9856, 0.9888, 0.9890, 0.9843, $0.9828,0.9827$ respectively) and $n$ being greater 0.5 suggesting non-Fickian diffusion process. ${ }^{12}$

\section{In vivo studies}

The study was carried out on male wistar albino rats to compare plasma concentration of Ramipril nanoparticles (optimised formulation F5) with that of pure drug given orally in normal saline.

In-vivo study revealed that formulation F5 showed greater bioavailability than that of the pure drug. The 
HPLC peaks of pure Ramipril and optimized formulation $\mathrm{F} 5$ at $1 \mathrm{hr}$ and at $12 \mathrm{hr}$ are shown in Figure 5, Figure 6, Figure 7 and Figure 8 respectively. AUC of $249.77 \mu \mathrm{g} / \mathrm{ml} \mathrm{hr}, \mathrm{C}_{\max }$ of $12.48 \mu \mathrm{g}$ and $\mathrm{T}_{\max }$ of $8 \mathrm{hr}$ was observed for formulation F5 given orally whereas pure drug showed AUC of $114.874 \mu \mathrm{g} / \mathrm{ml} \mathrm{hr}, \mathrm{C}_{\max }$ of $7.95 \mu \mathrm{g}$ and $\mathrm{T}_{\max } 0.5 \mathrm{hr}$ calculated by applying trapezoidal method. (Table 3)

$\mathrm{AUC}^{\circ}{ }_{-\mathrm{t}}$ of pure drug $114.874 \mu \mathrm{g} / \mathrm{ml} \mathrm{hr}$ was increased up to $249.77 \mu \mathrm{g} / \mathrm{ml}$ hr by Ramipril nanoparticle formulation through oral route. Figure 9 shows the comparative in vivo release profile of optimized formulation F5 and pure drug (Ramipril) after oral administration. Ramipril nanoparticles lead to enhancement of oral bioavailability by 2.17 times than that of pure drug. ${ }^{22}$

\section{Short term stability studies}

Stability studies were carried out on the optimized formulation F5 as per ICH guidelines for 90 days. By comparing this data with initial data it was observed that there was an slight decrease in the percentage entrapment efficiency and increase in particles size due to degradation of polymer and aggregation of particles. (Table 4) There was not much change in the drug release. Formulation stored at $\left(4 \pm 2{ }^{\circ} \mathrm{C}\right)$ showed bet-

Table 4: Effect on particle size, \% Entrapment efficiency, \% drug release during stability studies.

\begin{tabular}{|c|c|c|c|c|c|c|c|}
\hline & \multirow[b]{3}{*}{ Initial } & \multicolumn{6}{|c|}{ OPTIMISED FORMULATION F5 } \\
\hline & & \multicolumn{3}{|c|}{ Final at $5 \pm 3^{\circ} \mathrm{C}$} & \multicolumn{3}{|c|}{ Final at $30 \pm 20 \mathrm{C} / 65 \pm 5 \% \mathrm{RH}$} \\
\hline & & 30 days & 60 days & 90 days & 30days & 60 days & 90days \\
\hline Particle size $(\mathrm{nm})$ & $257.9 \pm 2.89$ & $260.5 \pm 3.8$ & $263.65 \pm 9.1$ & $270.35 \pm 4.8$ & $268.4 \pm 5.2$ & $273.9 \pm 0.9$ & $278.7 \pm 3.8$ \\
\hline $\begin{array}{l}\text { \% Entrapment } \\
\text { Efficiency }\end{array}$ & $86.7 \pm 0.001$ & $85.65 \pm 5.3$ & $83.62 \pm 13.2$ & $79.84 \pm 1.3$ & $83.76 \pm 8.0$ & $81.45 \pm 3.2$ & $74.84 \pm 2.3$ \\
\hline$\%$ Drug Release & $83.2 \pm 0.01$ & $81.7 \pm 1.54$ & $80.25 \pm 4.58$ & $77.34 \pm 4.1$ & $79.54 \pm 6.8$ & $75.78 \pm 1$ & $70.29 \pm 1.3$ \\
\hline
\end{tabular}

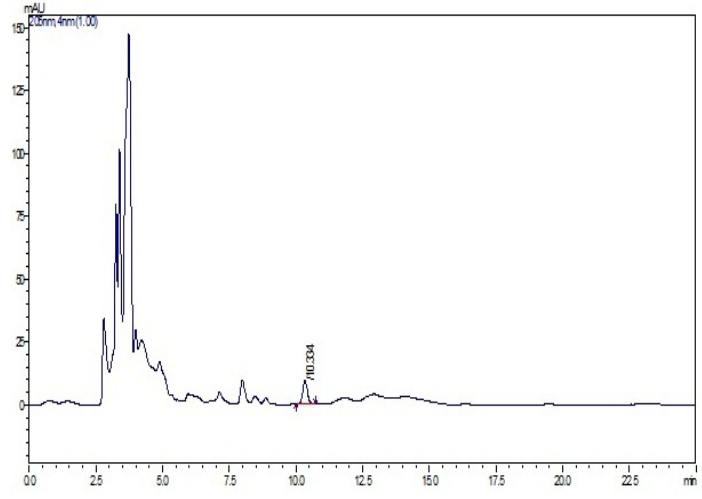

Figure 5: HPLC peak of Ramipril at $1 \mathrm{hr}$ (pure drug).

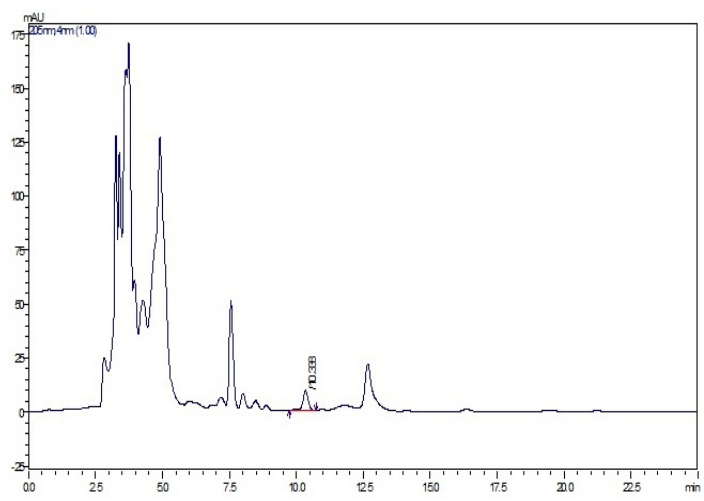

Figure 6: HPLC peak of Ramipril at 1hr (Optimized formulation F5).

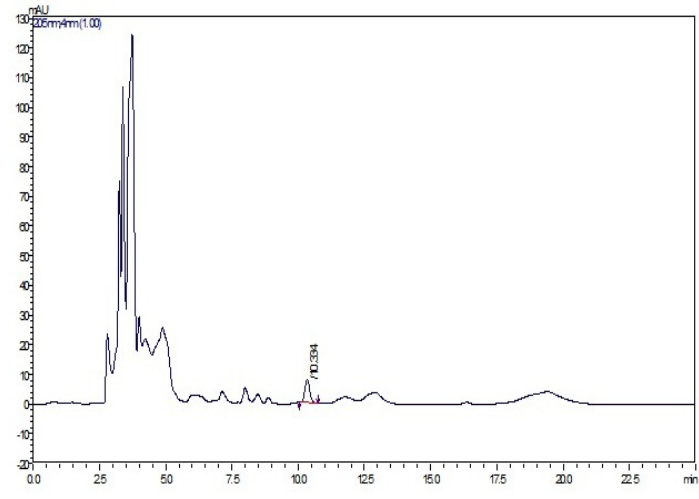

Figure 7: HPLC peak of Ramipril at 12hrs (pure drug).

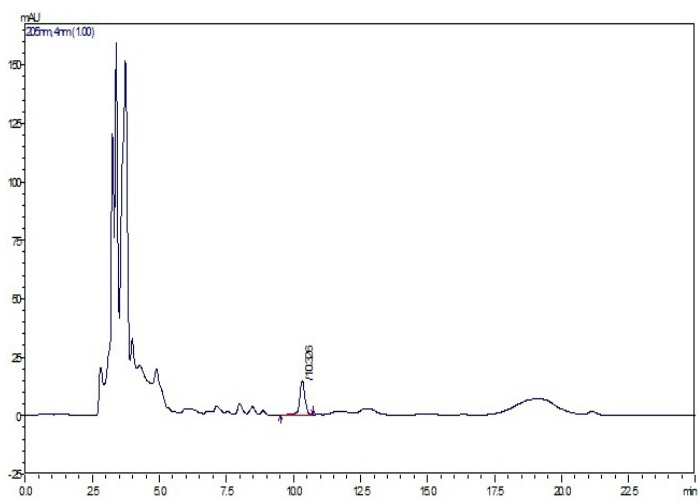

Figure 8: HPLC peak of Ramipril at $12 \mathrm{hrs}$ (optimized formulation F5). 


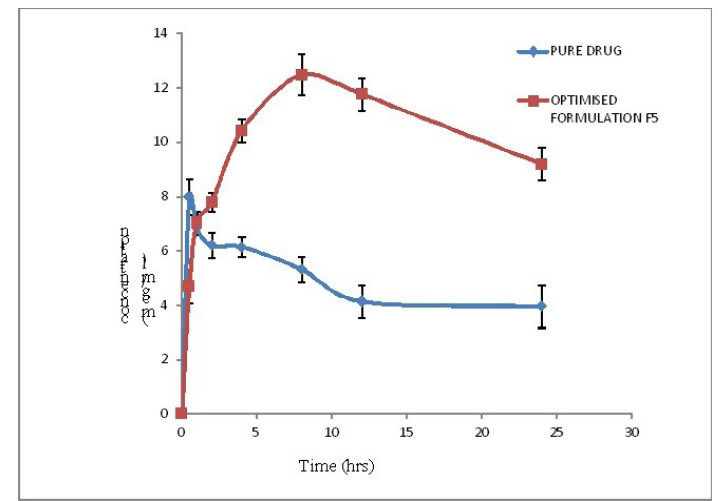

Figure 9: Comparative in vivo release profile of optimized formulation F5 and pure drug (Ramipril) by oral administration.

ter stability as compared to the formulation stored at $30 \pm 2{ }^{\circ} \mathrm{C} / 65 \pm 5 \% \mathrm{RH}$.

Ramipril chitosan- alginate nanoparticles can be successfully prepared by ionotropic pregelation technique. In vitro release study showed that chitosan- alginate nanoparticles showed $\mathrm{pH}$ dependent and sustained release of drug for a prolong period of time. The oral bioavailability of Ramipril when formulated into $\mathrm{pH}$ sensitive chitosan alginate nanoparticles was improved by 2.17 times the pure drug.

\section{ACKNOWLEDGEMENT}

The authors would sincerely like to thank Unichem Laboratories, Goa for providing gift samples of Ramipril and Central Institute of Fisheries Cochin, Kerala for providing chitosan. The authors are also grateful to KLE University's Dr. Prabhakar Kore Basic Science Research Centre, Belgaum for providing the laboratory facilities.

\section{CONFLICT OF INTEREST}

The authors declare no conflict of interest.

\section{ABBREVIATIONS}

ACE: Angiotensin-Converting Enzyme inhibitor; TEM: Transmission electron microscopy; HPLC: High performance liquid chromatography; ALG: Alginate; CS: Chitosan; PDI: Polydispersity index.

\section{REFERENCES}

1. Ekambaram P, Abdul HSA. Formulation and Evaluation of Solid Lipid Nanoparticles of Ramipril. Journal of Young Pharmacists. 2011;3(3):216-20.

2. Venkateswara R, Navaneetha K. Formulation and evaluation of sustain release tablets of Ramipril. Pharmatutor. 2014;2(7):110-9.

3. Motwani S, Chopra S, Talegaonkar S, Kohli K, Farhan JM. Chitosan-sodium alginate nanoparticles as submicroscopic reservoirs for ocular delivery:
Formulation, optimization and in vitro characterization. European Journal of Pharmaceutics and Biopharmaceutics. 2008;68(3):513-25.

4. Ranjit K, Abdul B. Nanoparticles: An overview preparation, characterization and applications. International Research Journal of Pharmacy. 2013;4(4):4857.

5. Ping L, Ya-Ni D, Jun-Ping Z, Ai-Qin W, Qin W. Chitosan-Alginate Nanoparticles as a novel drug delivery system for Nifedipine. International Journal of Biomedical Science. 2008;4(3):221-8.

6. Tarane G, Mohammad R, Ebrahim A, Parisa Y, Alireza N, et al. Evaluation of Alginate/Chitosan nanoparticles as antisense delivery vector: Formulation, optimization and in vitro characterization. Carbohydrate Polymers. 2009;77(3):599-606

7. Naser M, Azam B, Ali E, Heydari M. Preparation of chitosan nanoparticles containing Naja Naja Oxiana snake venom. Nanomedicine: Nanotechnology, Biology and Medicine. 2010;6(1):137-43.

8. Sangeetha S, Deepika K, Thrishala B, Chaitanya CH, Harish G, Damodharan $\mathrm{N}$. Formulation and in vitro evaluation of sodium alginate nanospheres containing Ofloxacin. International Journal Applied Pharmaceutical Sciences; 2010;2(4):1-3.

9. Nagarwal RC, Kumar R, Pandit JK. Chitosan coated sodium alginatechitosan nanoparticles loaded with 5-FU for ocular delivery: In vitro characterization and in vivo study in rabbit eye. European Journal of Pharmaceutical Sciences. 2012;47(4):678-85.

10. Kumari DC, Tharani CB, Narayanan N, Kumar S. Formulation and characterization of Methotrexate loaded sodium alginate chitosan Nanoparticles. Indian Journal of Research in Pharmacy and Biotechnology. 2015;1(6):915-21.

11. Dandagi P, Rath SP, Gadad AP, Mastiholimath V. Taste masked Quinine sulphate loaded solid lipid nanoparticles for flexible pediatric dosing. Indian Journal of Pharmaceutical Education and Research. 2014;48:93-9.

12. Prajapati MD, Kumar GS, Goli D, Maulik P, Shah H. Design, development and evaluation of nanoparticles of poorly soluble Valsartan. World Journal of Pharmacy and Pharmaceutical Sciences. 2013;2(6):5737-49.

13. Tamizhrasi S, Shukla A, Shivkumar T, Rathi V, Rathi J. Formulation And Evaluation of Lamivudine Loaded Polymethacrylic Acid Nanoparticles. International Journal of Pharmtech Research. 2009;1(3):411-5.

14. Kaur S, Rao R, Hussain A, Khatkar S. Preparation and Characterization of Rivastigmine Loaded Chitosan Nanoparticles. Journal of Pharmaceutical Sciences and Research. 2011;3(5):1227-32.

15. Jain S, Awasthi AM, Jain NK, Agrawal GP. Calcium silicate based microspheres of repaglinide for gastroretentive floating drug delivery: Preparation and in vitro characterization. Journal of Controlled Release. 2005;107(2):300-9.

16. Selvakumar K, Yadav AV. Formulation and Evaluation of Carvedilol loaded Eudragite 100 Nanoparticles. International Journal of Pharm Tech Research. 2009;1(2):179-83.

17. Sanyog J, Amit KJ, Nitin KS, Chandraiah G, Raman PS. The effect of the oral administration of polymeric nanoparticles on the efficacy and toxicity of tamoxifen. Biomaterials. 2011;32(2):503-15.

18. Sheikh S, Faiyaz S, Talegaonkar S, Farhan J, Mushir A. Development and bioavailability assessment of Ramipril nanoemulsion formulation. European Journal of Pharmaceutics and Biopharmaceutics. 2007;66(2):227-43.

19. Peng L, Xinyu R, Johanna L, Bert-Van V, Juha K, Jouni $H$, et al. Nanosuspensions of poorly soluble drugs: Preparation and development by wet milling. International Journal of Pharmaceutics. 2014;11:215-22.

20. Fei $Y$, Chao Z, Yi Zheng, Lin M, Lina T. The effect of poloxamer 188 on nanoparticle morphology, size, cancer cell uptake and cytotoxicity. Nanomedicine: Nanotechnology, Biology and Medicine. 2010;6(1):170-8.

21. Saleem V, Azharuddin SK, Ali S, Patil C. Studies on different chitosan polyelectrolyte complex hydrogels for modified release of Diltiazem Hydrochloride. International Journal of Pharmacy and Pharmaceutical Sciences. 2010;2(4):64-7.

22. Chouksey R, Kumar J, Pandey H, Maithil A. Development and bioavailability studies of Atorvastatin nanoemulsion. International Journal of Pharmacy and Life Sciences. 2011;2(8):982-8. 
PICTORIAL ABSTRACT

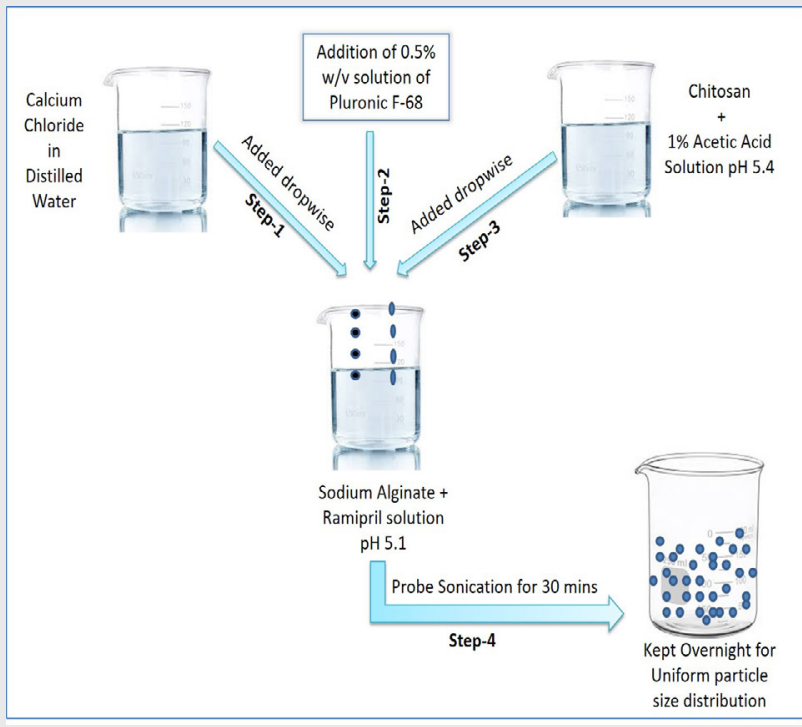

\section{SUMMARY}

- A total of nine formulations (F1-F9) were formulated by varying the concentration of chitosan (0.003\%-0.07\%) and sodium alginate (0.06-0.1\%) using ionotropic pregelation technique and the various parameters were evaluated.

- The size of nanoparticles were in nanosize range, spherical and discrete, particle size increase with increase in polymer concentration. Entrapment efficiency increased with increasing the polymer concentration to certain level and then decreased.

- F5 formulation was considered as optimized formulation based on higher entrapment efficiency, drug content and good Zeta potential of $-32.4 \mathrm{mV}$.

- In vitro release study showed initial burst effect, this may be due to drug present on the surface of nanoparticles followed by sustain release of drug.

- The oral bioavailability of Ramipril when formulated into $\mathrm{pH}$ sensitive CS-ALG nanoparticles was improved by 2.17 times more than that of pure drug. From the stability studies, it can be found that $5 \pm 300 \mathrm{C}$ is the ideal temperature for storage of nanoparticles.

\section{ABOUT AUTHORS}

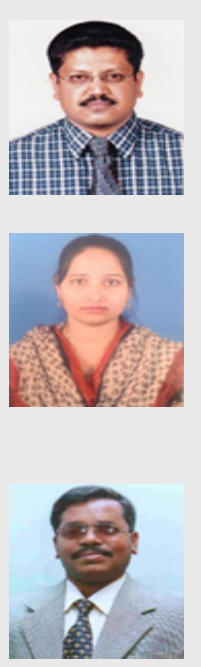

Anand Panchakshari Gadad: Is a Professor and Head, Department of Pharmaceutics, College of Pharmacy, K.L.E Academy of Higher Education and Research, Belagavi. He is working on areas of targeted drug delivery system viz., Gastroretentive drug delivery system, Polymeric nanoparticles, enhancing solubility of poorly soluble drugs, etc.

Archana S. Patil: Is an Assistan Professor, Department of pharmaceutics, KLE University's College of Pharmacy, K.L.E Academy of Higher Education and Research, Belagavi. She is working in the area of targeted drug delivery systems viz, $\mathrm{pH}$ and temperature responsive copolymeric nanoparticles, pulsatile drug delivery systems as well as synthesis and characterization of graft co-polymers for intelligent drug delivery etc.

Panchaxari Mallappa Dandagi: Is a Professor, Department of pharmaceutics, KLE University's College of Pharmacy, K.L.E Academy of Higher Education and Research, Belagavi. He is working on areas of targeted drug delivery system viz., Colon drug delivery system using $\mathrm{pH}$ dependent polymers and also Ocular drug delivery system through Nano and microspheres.

Cite this article: Pereira A, Gadad AP, Patil AS, Dandagi PM. Development and Bioavailability Assessment of Ramipril Nanoparticle Formulation. Indian J of Pharmaceutical Education and Research. 2019;54(4s):s587-s595. 